\title{
Pancreatitis aguda grave e infección por el virus de la influenza A (H1N1) en un paciente pediátrico: reporte de caso Severe acute pancreatitis and infection by influenza A (H1N1) virus in a child: case report
}

\author{
Dr. Diego Rodríguez Schulz, Dra. Agustina Martínez , Dra. María Belén Guzmán ${ }^{a}$ Dr. Hugo Robledo, \\ Dra. Patricia Capocasa ${ }^{a}$, Dra. Luz Martínez $z^{c}$ y Dra. Analía Garnero ${ }^{d}$
}

\begin{abstract}
RESUMEN
La pancreatitis aguda (PA) es una enfermedad inflamatoria del páncreas caracterizada por dolor abdominal y niveles elevados de enzimas pancreáticas. Representa la enfermedad pancreática más común de niños y adultos. Para el diagnóstico, se requieren 2 de los siguientes 3 criterios: dolor abdominal característico de PA, valores séricos de amilasa y/o lipasa 3 veces mayores que el límite superior normal y hallazgos característicos en las imágenes. Múltiples etiologías se han asociado: traumatismos, enfermedades metabólicas e infecciones (mixovirus, VIH, parotiditis, coxsackie, hepatitis B, A, citomegalovirus, varicela, herpes simple). Existen solo 3 casos reportados de PA asociados al virus de la influenza H1N1, solo uno en un niño y de características no complicadas.

Palabrasclave: pancreatitis, pancreatitis agudanecrotizante, subtipo H1N1 del virus de la influenza A, infección, virus.
\end{abstract}

\begin{abstract}
Acute pancreatitis is an inflammatory disease of the pancreas, characterized by abdominal pain and high level of pancreatic enzymes. Pancreatitis is the most common disease of pancreas in children and adults. For the diagnosis we need 2 of 3 characteristics: abdominal pain characteristic of acute pancreatitis, amylase and/or lipase 3 times higher than the normal upper limit and characteristic findings in images. The etiologies are multiple: trauma, metabolic disease and infections: mixovirus, HIV, measles, coxsackie, hepatitis B, C, cytomegalovirus, varicella, herpes simplex. Three cases of PA associated with H1N1 Influenza virus were reported, only one in a child with uncomplicated features.

Key words: pancreatitis, acute necrotizing pancreatitis, Infuenza A virus H1N1 subtype, infection, virus.
\end{abstract}

http:/ /dx.doi.org/10.5546/aap.2015.e215

a. Unidad de Terapia Intensiva.

b. Servicio de Diagnóstico por Imágenes.

c. Servicio de Clínica Pediátrica.

d. Servicio de Infectología.

Hospital de Niños de la Santísima Trinidad de Córdoba. Córdoba. Argentina.

Correspondencia:

Dr. Diego Rodríguez Schulz: diego_grs@hotmail.com

Financiamiento: ninguno.

Conflicto de intereses: ninguno que declarar.

Recibido: 17-12-2014

Aceptado: 16-3-2015

\section{INTRODUCCIÓN}

La pancreatitis aguda (PA), cuya incidencia en la población pediátrica está en aumento, se define como la presencia histológica de inflamación dentro del páncreas. Es una enfermedad inflamatoria del páncreas caracterizada por dolor abdominal y niveles elevados de enzimas pancreáticas.

La etiología de la PA es variada en la edad pediátrica: intoxicaciones, traumatismos, enfermedades metabólicas e infecciones. Entre estas últimas, se han descrito asociación con malaria, leptospirosis, VIH, parotiditis, ascaris, coxsackie, mycoplasma, mixovirus, hepatitis A y B, citomegalovirus, varicela, herpes simple 1 y 2, obstrucción biliar o periampular, drogas, causas vasculares, pos proteína $C$ reactiva (PCR), pancreatitis hereditaria, fibrosis quística $(\mathrm{FQ})$ y síndrome de Reye. ${ }^{1,2}$

Si bien es conocida la asociación con el virus de la influenza A, existen, al momento, solo 3 casos reportados de PA asociados al virus de la influenza H1N1, uno de ellos en un niño y todos clasificados como leves por su gravedad. ${ }^{2-4}$

Para su diagnóstico, ${ }^{5}$ se requieren 2 de los siguientes 3 criterios: dolor abdominal característico de PA, amilasa y/o lipasa sérica 3 veces mayor que el límite superior normal y hallazgos imagenológicos característicos o compatibles con PA, mediante ecografía o tomografía computada (TC). Se destaca el valor de esta última no como método de diagnóstico por imagen inicial, sino para confirmar el diagnóstico ante la sospecha de necrosis, estimar la gravedad, detectar complicaciones y proveer información para procedimientos intervencionistas. ${ }^{2,6}$ En la TC, encontramos un aumento del tamaño del páncreas (focal, segmentario o difuso) y un aumento de la densidad del tejido adiposo peripancreático secundario a inflamación o edema, pérdida del contorno acinar de la glándula, aumento del espesor de superficies fasciales vecinas y líquido en el sector pancreático. Cuando la glándula no se realza en forma homogénea y regular, indica necrosis glandular. 
Aunque en la población adulta están bien establecidos los criterios de gravedad según la última revisión de Atlanta del año 2013,7 actualmente, no hay consenso en la definición de la pancreatitis grave en niños. Pareciera, no obstante, haber cierto acuerdo en la inclusión de los siguientes criterios para definir la pancreatitis grave: presencia de complicaciones locales (necrosis estéril o infectada, hemorragia y absceso), desarrollo de disfunción de órganos y/o muerte secundaria a sus complicaciones. En relación con la pancreatitis necrotizante, esta presenta una incidencia en niños menor del 1\%, mientras que los pseudoquistes representan la complicación más frecuente en niños con PA grave, con una incidencia del 10 al 17\%. ${ }^{9}$

Respecto al pronóstico, existen, a la fecha, dos predictores de gravedad de PA en niños: la lipasa sérica ${ }^{10} \mathrm{y}$ el puntaje de gravedad de la pancreatitis aguda pediátrica (paediatric acute pancreatitis severity; PAPS, por sus siglas en inglés) ${ }_{1}^{11}$ que pueden ser utilizados dentro de las primeras $24 \mathrm{~h}$ y luego de las 48 h de su presentación, respectivamente. La tasa de mortalidad reportada en niños varía entre un 0 y un $17 \%$, y se relaciona, generalmente, con la enfermedad sistémica subyacente o traumatismos. ${ }^{12}$

\section{REPORTE DE UN CASO}

Ingresa al Servicio de Emergencias un paciente de sexo masculino de 2 años y 9 meses de edad, en época invernal, previamente sano, con vómitos de $24 \mathrm{~h}$ de evolución, medicado con metoclopramida vía oral (VO). Presenta, además, antecedentes de un registro febril, hiporexia, astenia y rinorrea en los últimos 5 días. Al momento del examen físico, se observa mal estado general, somnolencia con signos de deshidratación grave y/o de shock séptico (taquipnea, taquicardia, relleno capilar prolongado e hipotensión arterial con pulsos periféricos francamente disminuidos) con abdomen distendido y doloroso a la palpación aunque depresible.

Se indica resucitación hídrica y se realizan exámenes complementarios. El laboratorio revela leucocitosis con neutrofilia: $23640 / \mathrm{mm}^{3}$ leucocitos, con $1 \%$ de neutrófilos en cayado y $80 \%$ de neutrófilos segmentados; plaquetas: 298 000/mm³; PCR: 5 mg/L, acidosis metabólica descompensada ( $\mathrm{pH} 7,22, \mathrm{pCO}_{2} 49 \mathrm{mmHg}, \mathrm{pO}_{2}$ $40 \mathrm{mmHg}, \mathrm{HCO}_{3} 19,8 \mathrm{mmol} / \mathrm{L}$, saturación venosa $\mathrm{O}_{2} 62 \%$ ); con hiperlactacidemia (54 mg/dl) e hipoglucemia (52 mg/dl). Se realiza radiografía de tórax, que resulta normal, y ecografía abdominal, que muestra abundante cantidad de líquido libre (ascitis) e importante meteorismo, que dificulta la correcta valoración.

Con diagnóstico de abdomen agudo, se realiza laparotomía exploradora y se encuentra hemoperitoneo. En el posquirúrgico inmediato, presenta síndrome de respuesta inflamatoria sistémica (SIRS) e ingresa a la Unidad de Terapia Intensiva.

Se solicita amilasa (1470 U/L), lipasa (853 U/L) y TC de abdomen con contraste endovenoso (Figuras 1. $A$ y B): aumento difuso de tamaño del páncreas, principalmente del cuerpo y cola, con bordes mal definidos, heterogéneo, hipodenso; queda tan solo reforzada con contraste la parte más distal de la cola. Importante cantidad de líquido libre. Hallazgos a favor de pancreatitis con gran componente necrótico, de aproximadamente el $90 \%$. Según la clasificación de Balthazar, ${ }^{13}$ corresponde al grado D y, como presenta una necrosis mayor del 50\%, el índice de gravedad en la TC correspondiente es alto.

En la búsqueda de la etiología, se descartan antecedentes personales y familiares de enfermedades sistémicas, traumatismos, ingesta de tóxicos e hiperlipidemia. Se realiza pesquisa para etiología infecciosa: serología negativa ( $\operatorname{IgG}$ e IgM) para el virus del herpes simple tipo 1 y 2, citomegalovirus, virus de Epstein Barr, virus de la hepatitis B y C, y VIH. Dada la época del año y el antecedente de rinorrea, se realiza hisopado nasal, que resulta positivo para el virus de la influenza A, con PCR positiva para $\mathrm{H} 1 \mathrm{~N} 1$, por lo que cumple 5 días de tratamiento con oseltamivir de $45 \mathrm{mg}$ cada $12 \mathrm{~h}$.

A $48 \mathrm{~h}$ de su ingreso, con puntaje de PAPS de 7 , presenta fallo multiorgánico respiratorio con síndrome de dificultad respiratoria aguda -SDRA- y requiere asistencia ventilatoria mecánica, cardiovascular sostenido con agentes vasoactivos, renal con diuresis a expensas de furosemida, hepático (transaminasa glutámicopirúvica -GPT-: $84 \mathrm{U} / 1)$ y hematológico (plaquetas: $68000 / \mathrm{mm}^{3}$ ) y diabetes mellitus secundaria con requerimientos de insulina.

Luego de la primera semana de haber estado internado, lograda relativa estabilidad, presenta nuevamente SIRS al día 11 de internación. Se toman muestras para hemocultivos, retrohemocultivo, urocultivo y cultivo de material de colección pancreática y se adiciona empíricamente vancomicina, imipenem y metronidazol por sospecha de shock séptico vs. necrosis pancreática infectada. Se realiza 
ecografía abdominal, que informa páncreas aumentado de tamaño con colección anecoica, de bordes definidos y con membranas en su interior de $71 \mathrm{~mm}$ x $87 \mathrm{~mm}$ sin líquido libre. Se realiza una punción de colección pancreática bajo guía ecográfica y colocación de drenaje, y se obtiene líquido de aspecto necrótico. El examen citológico muestra 164 elementos $/ \mathrm{mm}^{3}, 65 \%$ polimorfonucleares y $35 \%$ mononucleares con frecuentes hematíes y amilasa de $8432 \mathrm{U} / \mathrm{L}$.

Luego de la evacuación de la colección, el paciente evoluciona favorablemente y supera el fallo multiorgánico. Con cultivos negativos, y dada la ausencia de evidencia acerca de su utilización en PA, se retira la antibioticoterapia y comienza con alimentación enteral. El drenaje abdominal se retira a los 8 días y se extuba a los 25 días de internación. A los 29 días de haber estado internado, pasa a sala de menor complejidad desde donde es dado de alta al cabo de 10 días con requerimientos de insulina corriente e insulina protamina neutra Hagedorn (Neutral Protamine Hagedorn; NPH, por sus siglas en inglés) y dieta hipograsa sin azúcares simples.

\section{DISCUSIÓN}

Establecer la causa de la pancreatitis aguda en niños es un proceso, muchas veces, dificultoso, puesto que, en contraste con la población adulta, en la que la etiología biliar y alcohólica representa más del $65 \%$ de los casos, ${ }^{14}$ en niños, las causas son más variadas. Respecto a la etiología infecciosa, esta supone menos del 10\% de las causas de pancreatitis aguda en niños, y discriminar entre causalidad o simple asociación temporal no resulta sencillo, por lo que estas se clasifican como de etiología infecciosa definitiva, probable o posible según la evidencia de causalidad que presenten. ${ }^{1}$

En lo que respecta al virus de la influenza A (H1N1), como agente etiológico de PA, un reciente artículo ${ }^{15}$ realizado in vivo en aves del género Meleagris, familia Phasianidae e in vitro en células pancreáticas humanas sugiere que el páncreas podría ser un órgano diana de la infección por influenza A (incluido H1N1) y jugar un rol importante en la etiopatogénesis de la pancreatitis e, incluso, de la diabetes mellitus en humanos.

Además, existen únicamente tres casos reportados a la comunidad científica de pancreatitis aguda relacionada con influenza A (H1N1), ${ }^{2-4}$ uno de ellos pediátrico. El presente caso posee la particularidad de ser el único con características de pancreatitis aguda grave según la clasificación de Atlanta utilizada en adultos, ${ }^{7}$ dada la presencia de fallo orgánico persistente.

Para ampliar la información acerca de la

FigURAS 1 A y B. Tomografía computada de abdomen con contraste endovenoso: aumento difuso del tamaño del páncreas, con bordes mal definidos heterogéneos (flecha roja), hipodenso, con refuerzo solo en la parte distal de la cola (flecha verde). Líquido libre (asterisco azul). A. Corte axial de tomografía computada de abdomen. B. Corte coronal de tomografía computada de abdomen

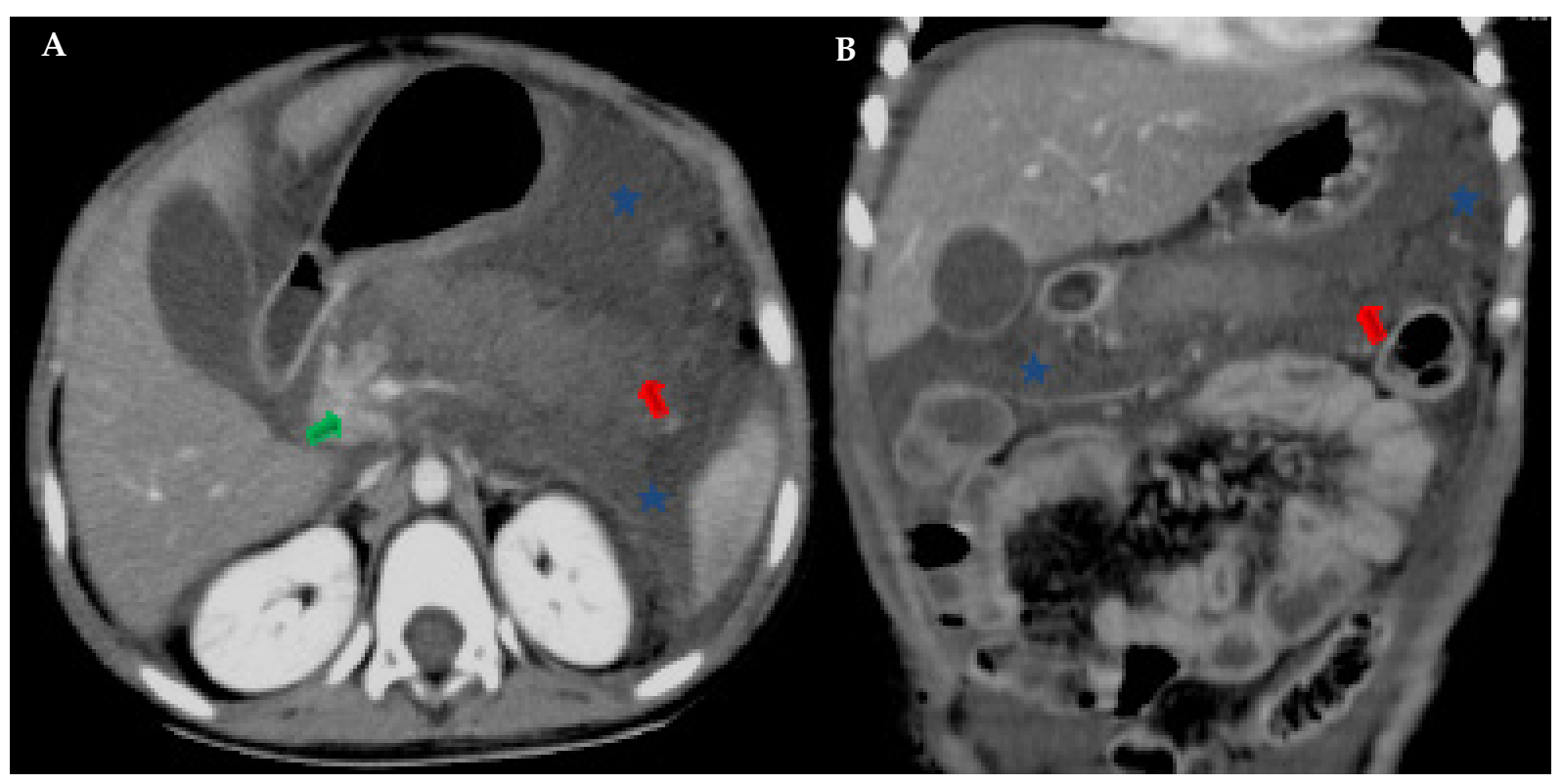


causalidad de la pancreatitis aguda por el virus de la influenza A (H1N1), proponemos la pesquisa de este agente etiológico en todo paciente con pancreatitis aguda en época invernal, una vez descartadas las causas más prevalentes de esta entidad nosológica.

\section{REFERENCIAS}

1. Parenti DM,Steinberg W, Kang P. Infectious causes of acute pancreatitis. Pancreas 1996;13(4):356-71.

2. Baran B,Karaca C, SoyerOM,LacinS, etal. Acutepancreatitis associated with H1N1 influenza during 2009 pandemic: a case report. Clin Res Hepatol Gastroenterol 2012;36(4):e69-70.

3. Blum A, Podvitzky O, Shalabi R, Simsolo C. Acute pancreatitis may be caused by H1N1 influenza A virus infection. Isr Med Assoc J 2010;12(10):640-1.

4. Sánchez Bautista A, Alcalá Minagorre PJ, Segura Sánchez S, Mira-Perceval Juan G. Infección por virus de la gripe A (H1N1) 2009 pandémico tratada con oseltamivir y posible asociación con pancreatitis aguda en una paciente de 12 años. Enferm Infecc Microbiol Clin 2015;33(2):139-40.

5. Morinville VD, Husain SZ, Bai H, Barth B, et al. Definitions of pediatric pancreatitis and survey of present clinical practices. J Pediatr Gastroenterol Nutr 2012;55(3):261-5.

6. Bai HX, Lowe ME, Husain SZ. What have we learned about acute pancreatitis in children? J Pediatr Gastroenterol Nutr 2011;52(3):262-70.
7. Banks PA, Bollen TL, Dervenis C, Gooszen HG, et al. Classification of acute pancreatitis--2012: revision of the Atlanta classification and definitions by international consensus. Gut 2013;62(1):102-11.

8. Whitcomb DC, Lowe ME. Pancreatitis: acute and chronic. En: Kleinman RE, Sanderson IR, Goulet O, Sherman PM, et al, eds. Walker's pediatric gastrointestinal disease. $5^{\text {th }}$ ed. Hamilton: BC Decker Inc; 2008. Págs.1213-20.

9. Lerner A, Branski D, Lebenthal E. Pancreatic diseases in children. Pediatr Clin North Am 1996;43(1):125-56.

10. Coffey MJ, Nightingale S, Ooi CY. Serum lipase as an early predictor of severity in pediatric acute pancreatitis. J Pediatr Gastroenterol Nutr 2013;56(6):602-8.

11. DeBanto JR, Goday PS, Pedroso MR, Iftikhar R, et al. Acute pancreatitis in children. Am J Gastroenterol 2002;97(7): 1726-31.

12. Meyer A, Coffey MJ, Oliver MR, Ooi CY. Contrasts and comparisons between childhood and adult onset acute pancreatitis. Pancreatology 2013;13(4):429-35.

13. Balthazar EJ, Robinson DL, Megibow AJ, Ranson JH. Acute pancreatitis: value of $\mathrm{CT}$ in establishing prognosis. Radiology 1990;174(2):331-6.

14. Tenner S, Baillie J, DeWitt J, Vege SS. American College of Gastroenterology guideline: management of acute pancreatitis. Am J Gastroenterol 2013;108(9):1400-15.

15. Capua I, Mercalli A, Pizzuto MS, Romero-Tejeda A, et al. Influenza A viruses grow in human pancreatic cells and cause pancreatitis and diabetes in an animal model. J Virol 2013;87(1):597-610. 